\title{
REVIEW \\ Newborn healthcare in urban India
}

\author{
J Sharma ${ }^{1}$, D Osrin ${ }^{2}$, B Patil ${ }^{3}$, SB Neogi ${ }^{1}$, M Chauhan ${ }^{1}$, R Khanna ${ }^{3}$, R Kumar $^{4}$, VK Paul $^{5}$ and S Zodpey ${ }^{1}$
}

The rapid population growth in urban India has outpaced the municipal capacity to build essential infrastructures that make life in cities safe and healthy. Local and national governments alike are grappling with the challenges of urbanization with thousands migrating from villages to cities. Thus, urbanization in India has been accompanied by a concentration of poverty and urban public healthcare has emerged as one of the most pressing priorities facing our country. Newborn mortality rates in urban settings are lower than rural areas, early neonatal deaths account for greater proportion than late neonatal deaths. The available evidence suggests that socio-economic inequalities and poor environment pose major challenges for newborn health. Moreover, fragmented and weak public health system, multiplicity of actors and limited capacity of public health planning further constrain the delivery of quality and affordable health care service. Though healthcare is concentrated in urban areas, delay in deciding to seek health care, reaching a source of it and receiving appropriate care affects the health outcomes disproportionately. However, a few city initiatives and innovations piloted in different states and cities have brought forth the evidences of effectiveness of different strategies. Recently launched National Urban Health Mission (NUHM) provides an opportunity for strategic thinking and actions to improve newborn health outcomes in India. There is also an opportunity for coalescence of activities around National Health Mission (NHM) and Reproductive, Maternal, Newborn and Child Health+Adolescent (RMNCH+A) strategy to develop feasible and workable models in different urban settings. Concomitant operational research needs to be carried out so that the obstacles, approaches and response to the program can be understood.

Journal of Perinatology (2016) 36, S24-S31; doi:10.1038/jp.2016.187

\section{BACKGROUND}

The unprecedented growth of urban population in India is posing a daunting challenge to build essential infrastructures that make life in cities safe and healthy. The 2011 Census describes an urban population of over 377 million within a total population of 1.21 billion, which is expected to grow to 590 million by $2030{ }^{1,2}$ Urban Indians live in 7935 towns and cities, of which 468 have populations of at least 100000 and house $70 \%$ of urban residents. Of the 53 cities that have populations of over one million, three of these, Mumbai, Delhi, and Kolkata are mega-cities of over 10 million. India's urban growth has been described as following a '2$3-4-5$ ' pattern: annual population growth of $2 \%$, urban population growth of $3 \%$, mega-city growth of $4 \%$ and slum population growth of $5 \% .^{3,4}$ The challenge of urbanization is accompanied by a growing concentration of poverty with thousands migrating from villages to cities. Many of these migrants ultimately end up living in slums, where non-waged informal employment is the dominant characteristic of their livelihoods. ${ }^{5-8}$ According to the most recent estimates for 2011-2012, 14\% of urban people are below a poverty line of Rs. 1000 per person per month (compared with $26 \%$ of rural people, at a poverty line of Rs.816). ${ }^{9,10}$

While India awakens to the challenges of urban health, the reality is that the mega-cities have functional municipal corporations with a long history of grappling with urban concerns andat least to some degree-the health of their people. City dwellers are often oversupplied with healthcare choices. State government hospitals and municipal facilities at primary, secondary and tertiary levels are accompanied by private sector providers from
Allopathic, Ayurvedic, Unani, Siddha and Homoeopathic traditions (AYUSH). From single-handed practitioners to super-specialty hospitals, the market provides something for everyone-from the richest to the poorest-and this raises the fundamental challenges of quality more than quantity or availability of services. ${ }^{11}$ However, in rapidly growing smaller towns, the healthcare systems are more vulnerable with less prepared governmental bodies, less available health care options and thus more fragile and fragmented health services.

\section{URBAN NEWBORN HEALTH}

Findings from the Sample Registration System and the Annual Health Survey (covering 284 districts of 9 high priority states), institutional records and isolated studies (Figures 1 and 2) illustrate the steady fall in neonatal mortality rates over a decade, which is lower overall in urban than in rural areas, and also reflect the relative lack of progress in reducing early neonatal mortality. Reliable and disaggregated urban data especially the data related to slums focusing on the most vulnerable city dwellers (that are frequently not counted) is completely absent.

Figure 3 through $6^{12,13}$ presents a series of findings from urban districts. These data show that urban NMR varies from 12 in Jharkhand to 20 per 1000 live births in Uttar Pradesh, raising the question about under-reporting above the reported range itself. Institutional delivery in urban areas ranges between $60 \%$ and $90 \%$, duration of hospital stay varies widely and early breastfeeding is reported as ranging from $40 \%$ to $70 \%$. Low birth weight continues

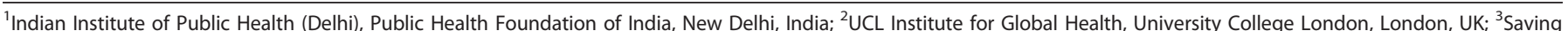

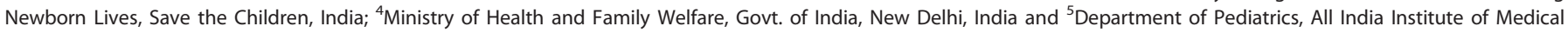

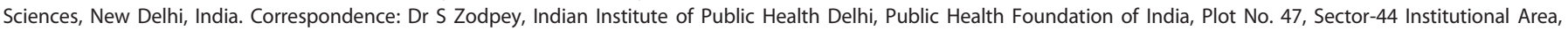
Gurgaon 122002, New Delhi, India.

E-mail: sanjay.zodpey@phfi.org 


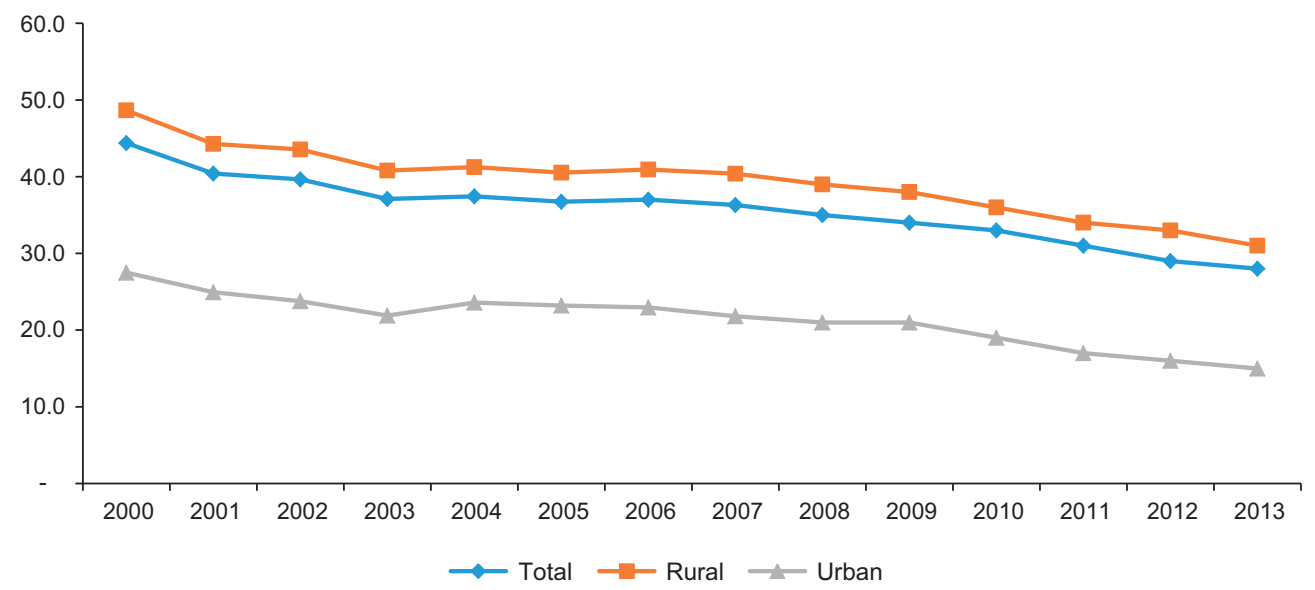

Figure 1. Neonatal Mortality Rates by rural and urban residence. Adapted with permission from Registrar General of India. Sample Registration System (SRS) Statistical Report, New Delhi. Available from http://www.censusindia.gov.in/2011-common/Sample_Registration_System.html. Copyright 2013, Office of the Registrar General and Census Commissioner, India. Copyright 2013, Office of the Registrar General and Census Commissioner, India.

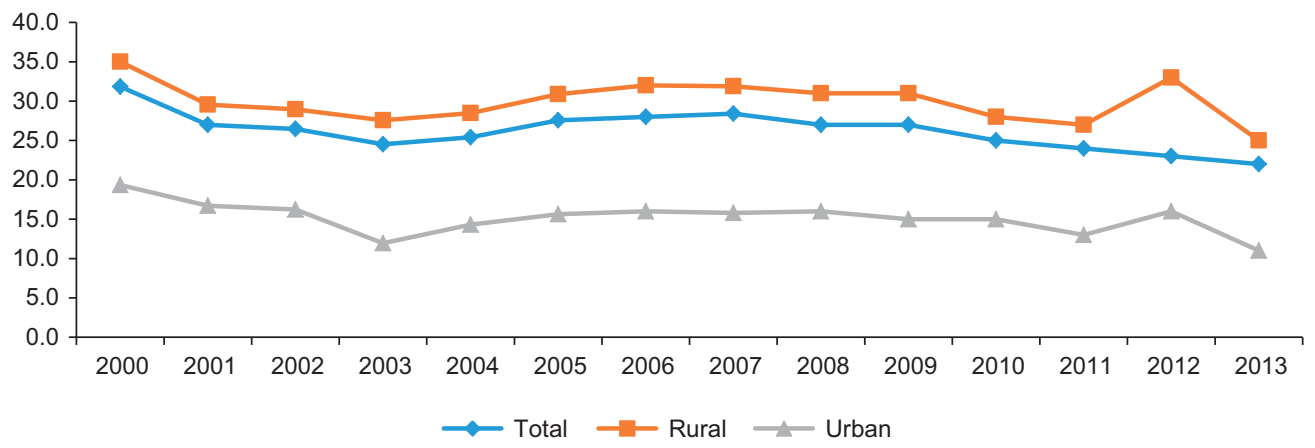

Figure 2. Early Neonatal Mortality Rates by rural and urban residence. Adapted with permission from Registrar General of India. Sample Registration System (SRS) Statistical Report, New Delhi. Available at http://www.censusindia.gov.in/2011-common/Sample_Registration_System.html. Copyright 2013, Office of the Registrar General and Census Commissioner, India.

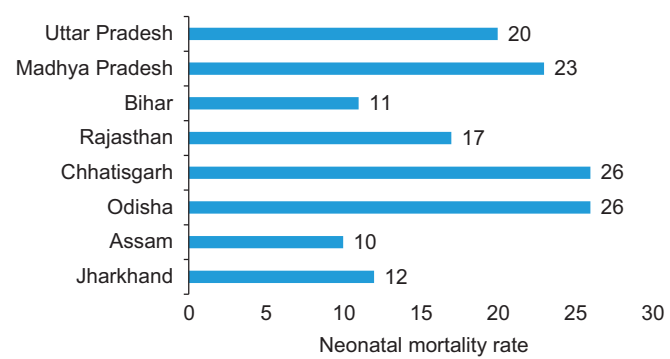

Figure 3. Neonatal Mortality Rates by urban residence in selected states. Adapted with permission from Registrar General of India. Sample Registration System (SRS) Statistical Report, New Delhi. Available at http://censusindia.gov.in/2011-common/Sample_Registration_System.html. Copyright 2013, Office of the Registrar General and Census Commissioner, India.

to be a common aspect in all states, with particular prevalence in Madhya Pradesh and Rajasthan Figure 4.

\section{CAUSES OF NEWBORN MORTALITY}

The causes of stillbirth and newborn deaths in the urban areas are similar to those in the rural areas, with some difference in the

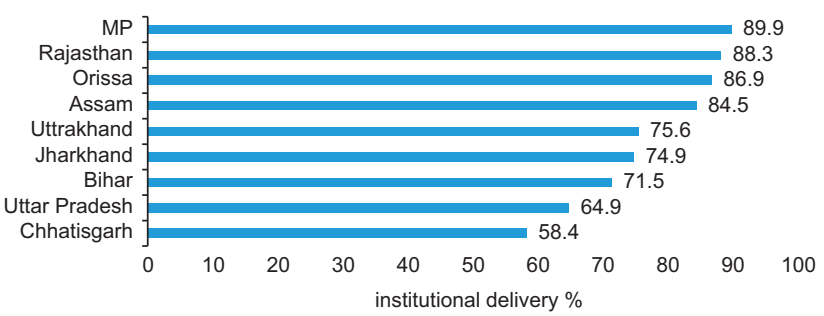

Figure 4. Urban Institutional Delivery percentage, in 9 Empowered Action Group ( EAG) states. Adapted with permission from Office of the Registrar General \& Census Commissioner- Ministry of Home Affairs, Govt. of India. Annual Health Survey (2012-13). Available at: http://www.censusindia.gov.in/2011-Common/AHSurvey.html.

Copyright 2013, Office of the Registrar General and Census Commissioner, India.

proportional breakdown. Although few studies have examined the causes of newborn mortality in urban India, the evidence from one of the studies in Mumbai slums reflects that $75 \%$ of neonatal deaths occurred in the first week. Intrapartum-related deaths contributed $28 \%$, prematurity $23 \%$ and severe infection $22 \%$ to neonatal deaths. ${ }^{14}$ In a study of 120 neonatal deaths from Vellore, $39 \%$ were ascribed to asphyxia and $21 \%$ to prematurity. ${ }^{15}$ 


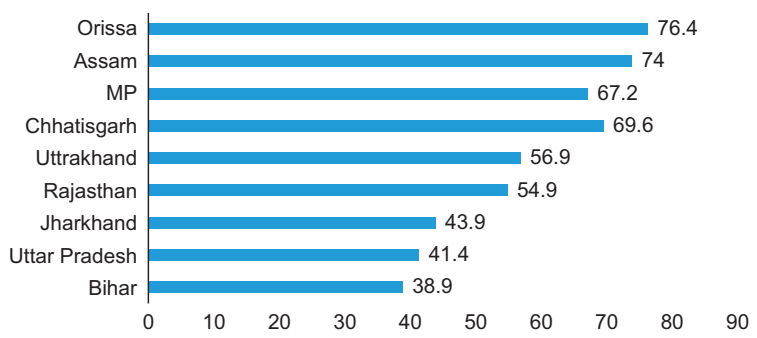

Figure 5. Urban percentage of newborns breastfed within one hour of birth, in 9 EAG states. Adapted with permission from Office of the Registrar General \& Census Commissioner- Ministry of Home Affairs, Govt. of India. Annual Health Survey (2012-13). Available at: http://www.censusindia.gov.in/2011-Common/AHSurvey.html.

Copyright 2013, Office of the Registrar General and Census Commissioner, India.

\section{TOWARD BETTER URBAN NEWBORN HEALTH}

\section{Evidence on urban health initiatives}

A recent commission on healthy cities recommended the option of trying a range of approaches for improving urban health and choosing successful features from among them. ${ }^{16}$ A few city initiatives and innovations in Uttar Pradesh, Maharashtra and Gujarat have provided evidence of effectiveness of some innovative strategies. However, by and large, the service delivery structure and mechanisms in the urban areas continue to be rudderless with complete lack of clarity on roles and responsibilities as compared with rural areas, where the district administration is structured and responsible for service provision. In addition, lack of demonstrated political will to assume responsibility and accountability for urban services as well as absence of interdepartmental coordination between the Departments of Public Health, Urban Development, Medical Education, the Municipal Corporations and the local bodies have compounded the problem further.

Through policy dialogue, the Government of Gujarat and the Urban Health Alliance have addressed public-private partnership in a number of ways. Major initiatives include the Chiranjivi Yojana and the Balsakha Yojana, both of which aim to improve newborn survival. ${ }^{17-19}$ In 2005, a chain of hospitals (life spring initiative) was set up in Hyderabad, Andhra Pradesh, through a partnership between Acumen Fund, a private enterprise social fund, and HLL Life-care, a public sector company. The model is for-profit but aims at cost-minimization through the use of leased buildings, collaboration with government ambulance services, deployment of nurse administrators and auxiliary nurse midwives, and careful stock control for pharmaceuticals and consumables. A similar initiative was tried in Uttar Pradesh. A study in urban Lucknow in Uttar Pradesh examined the effect of behavior change communication in two public hospitals on newborn care-seeking with qualified clinicians. Mothers were counseled and provided with a Neonatal Well-Being Card (Navjat Shishu Raksha Card). Odds of consulting a qualified practitioner for infants who had any morbidity doubled after the intervention (OR 2.12 (1.42-3.16)). ${ }^{20}$ Urban Health Resource Centre (UHRC) in Indore demonstrated the potential of capable community volunteers and organizations, primarily women's groups, in improving health of slum communities. $^{21}$

Along with $\mathrm{BCC}$, social mobilization should be a component of efforts to improve perinatal health. ${ }^{22}$ In Mumbai, SNEHA (Society for Nutrition, Education and Health Action) introduced a combination of supply and demand-side approaches to newborn health in slum communities. ${ }^{23}$ One axis sought to address low uptake of antenatal care at health posts, lack of protocols for case management, disorganized referral systems, and technical and

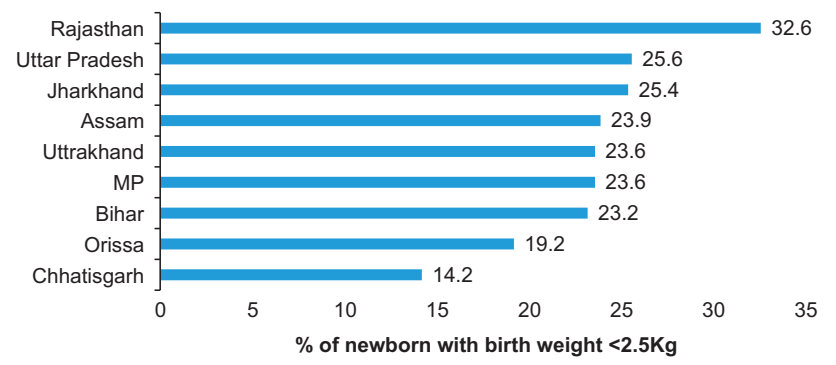

Figure 6. Proportion of newborns with low birth weight $(<2500 \mathrm{~g})$, in urban areas in nine EAG states. Adapted with permission from Office of the Registrar General \& Census Commissioner- Ministry of Home Affairs, Govt. of India. Annual Health Survey (2012-13). Available at: http://www.censusindia.gov.in/2011-Common/AHSurvey.html. Copyright 2013, Office of the Registrar General and Census Commissioner, India.

interpersonal skill deficiencies among public healthcare workers. The other axis hoped to build on the success of community participation through women's groups, which has improved newborn (and maternal) survival in rural south Asia. Analysis of over 18000 births over three years did not find improvements in the utilization of antenatal care, institutional delivery, early and exclusive breastfeeding, care seeking or perinatal mortality. The inferences were that the community-based work should target the most vulnerable groups more effectively, that newborn health should be integrated with other concerns and that quality of care continues to be an issue. ${ }^{24,25}$

The Gujarat Urban Health Alliance has supported Government of Gujrat to strengthen primary healthcare delivery system in the urban areas and attempted to achieve convergence through a series of urban plans: a health system plan; a health administrative structural plan including state, regional and zonal bodies; a reproductive and child health service plan; a health monitoring plan and the formation of urban health societies.

The Urban Health Initiative (UHI) is a part of a multi-country family planning effort to improve contraceptive use and reduce unplanned pregnancy as a key strategy to improve maternal and infant survival. UHI strategies facilitated increased access to services and supplies, and improved communication to increase and sustain the demand. UHI works in 1802 slums in all 11 cities of Uttar Pradesh. UHI supported the cities, which reported 148895 new users of modern contraceptives, including 87043 acceptors of long acting and permanent family planning methods since 2010.

Implemented by PATH, the Sure Start initiative aimed to improve maternal and newborn health through action in slums in seven cities in Maharashtra. In each case, a common minimum program was implemented and city-specific models developed in partnership with NGOs, academic institutions, public health training institutions and municipal corporations piggy-backed on it. The results showed increased utilization of maternal and child health services, and improved service quality. The initiatives also helped in community mobilization. ${ }^{26}$

\section{Policy initiatives}

Urban Family Welfare Centres (UFWCs) have been functioning in India since the first family planning program launched in 1952. In the 1980s, as a result of the recommendations of the Krishnan Committee Report, 1982, Urban Health Posts (UHPs) were opened to provide primary healthcare for the urban slums and the urban poor. Over the years, various committees such as the Bhore Committee 1946, Jungalwalla Committee 1967, Bajaj Committee 1996, Mashelkar Committee 2003 and the National Commission on Macroeconomics and Health 2005 have suggested ways to 
Table 1. Structural and human resource propositions of the National Urban Health Mission (NUHM)

\begin{tabular}{ll}
\hline Proposition & Serving \\
\hline Urban Primary Health Centre (U-PHC) & $50000-60000$ population \\
Urban Community Health Centre ( U-CHC) & $250000-360000$ population \\
& $5-6$ U-PHCs in larger cities \\
Auxiliary Nurse Midwife ( ANM) & 10000 population \\
Accredited Social Health Activist (ASHA) (Urban Social Health Activist) (USHA) & $200-500$ households \\
& $1000-3000$ population
\end{tabular}

Source: Adapted with permission from National Health Mission, National Urban Health Mission (NUHM) Framework, Ministry of Health and Family Welfare, Govt. of India, New Delhi. Copyright 2013: Child Health Division, Ministry of Health and Family Welfare.

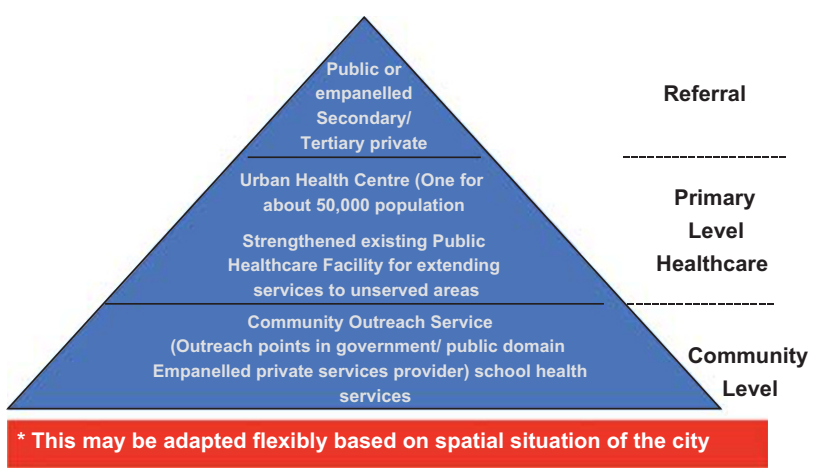

Figure 7. Urban Health Care delivery model. Reused with permission from National Health Mission, National Urban Health Mission (NUHM) Framework, Ministry of Health and Family Welfare, Govt. of India, New Delhi. Copyright 2013: Child Health Division, Ministry of Health and Family Welfare.

strengthen the health sector. Subsequently, the Ministry of Health and Family Welfare in 2013 has launched a National Urban Health Mission (NUHM) besides NRHM launched in 2005.

Since urban health involves the convergence of the domains, a number of programs and policies implemented by other sectors such as the Ministry of Housing and Urban Poverty Alleviation are also very important. Jawaharlal Nehru National Urban Renewal Mission (JNNURM-2009) covers the provision of the basic services for the urban poor (BSUP). The Swarna Jayanti Shahari Rozgar Yojana (SJSRY, revised 2009) targets skill development for livelihoods. Other relevant schemes include Affordable Housing in Partnership (AHIP), the Interest Subsidy Scheme for Housing the Urban Poor (ISHUP) and the Integrated Low Cost Sanitation Scheme (ILCS). Launched by the Prime Minister in 2009, the Rajiv Awas Yojana (RAY) envisages a slum-free India and proposes affordable housing by merging the AHIP and ISHUP.

\section{URBAN HEALTH STRUCTURES AND MECHANISMS: KEY ASPECTS}

- The ultimate responsibility of providing health services in urban areas is not clear as it is in rural areas where the district administration is in charge of public health.

- All resources invested in urban healthcare deal primarily with curative services.

- Urban health posts mainly provide three types of services: Regular (including preventive, curative, IEC activities and training), seasonal (pre-monsoon and monsoon-related activities) and disaster management.

- The urban healthcare system is focused on secondary and tertiary care, and not on primary level services.

\section{SERVICE PROVISION: KEY ASPECTS}

- Health services vary from city to city. Some cities have a wellestablished ICDS in place. A few large cities like Mumbai, Kolkata and Chennai have focused on the health infrastructure establishment in urban slums.

- Only a few large municipal Corporations with good revenue resources have demarcated special resources to provide urban health services.

- Referral services are available in corporation hospitals/district hospitals/medical college hospitals as well as several private hospitals.

- There is no mechanism for a health worker to make community or home visits and thus no outreach and follow-up services are available.

- There is no definite system of referral; no linkages between domiciliary, health centre, and hospital; and no protocols for admissions to primary, secondary, and tertiary levels.

- A link worker or community health volunteer has been appointed in a few cities that are effectively implementing the NRHM (Urban Component) and RCH II project. The main role of the link worker is family welfare, maternal and child health, immunization, health education and demand generation.

\section{NATIONAL URBAN HEALTH MISSION}

The Government of India's Twelfth Plan builds on the National Rural Health Mission (NHRM) and converts it into a National Health Mission for the whole country. In doing so, it incorporates the developing National Urban Health Mission (NUHM) as a submission. NUHM endeavors to achieve its goal specifically through a need-based city-specific urban healthcare system that will meet the diverse healthcare needs of the urban poor and other vulnerable sections and through public health management systems to meet the health-related challenges of a rapidly growing urban population. Focusing on the primary healthcare needs of the urban poor, the NUHM is being implemented in 779 cities and towns having populations of more than 50000 each.

The NUHM framework for the implementation provides one U-PHC for every 50000 population (See Table 1 and Figures 7 and 8). This would be achieved by both adapting and upgrading existing facilities and adding new ones. In response to the needs for convergence and public health management, the NUHM plans that every Municipal Corporation, municipality, Notified Area Committee and town Panchayat will be a planning unit in its own right with its own approved norms for setting up healthcare facilities. These local bodies will prioritize services for the urban poor (in both listed and unlisted slums) and for vulnerable groups such as the homeless, rag pickers, street children, rickshaw pullers, construction and brick and lime kiln workers, and sex workers. Sanitation, clean drinking water, and vector control will be central to the public health remit. 27,28 


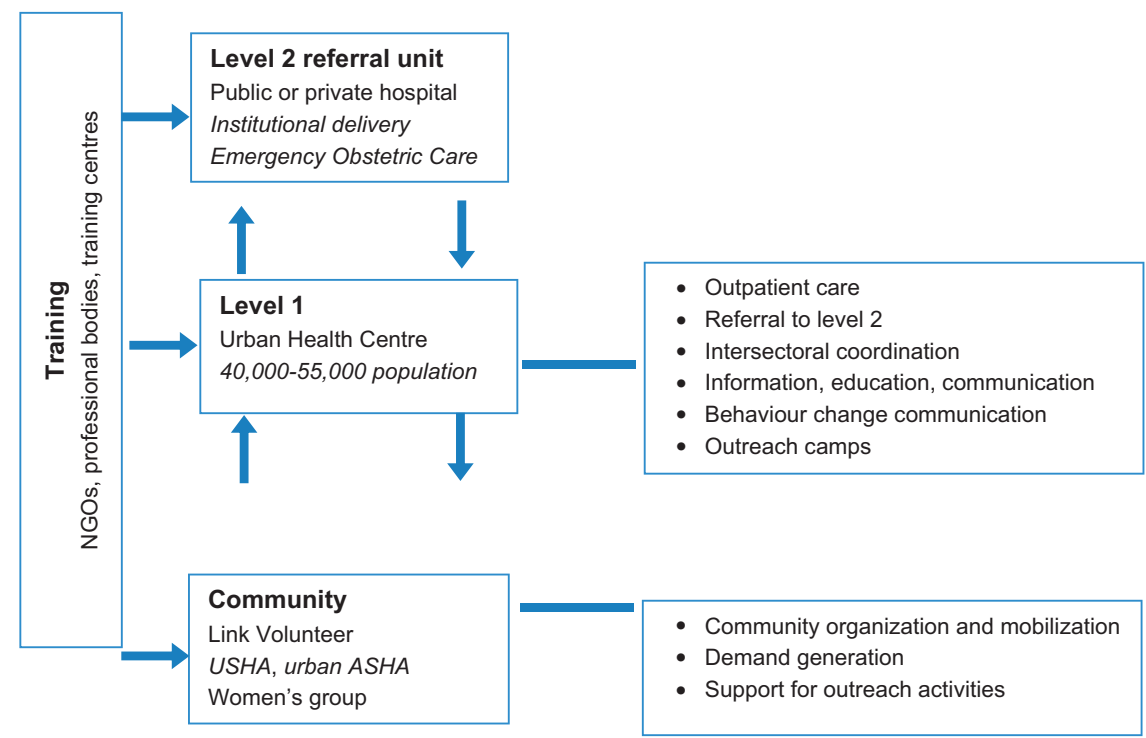

Figure 8. Reproductive, Maternal, Newborn and Child Health+Adolescent $(\mathrm{RMNCH}+\mathrm{A})$ service package for urban areas.

Table 2. Multiple service providers for maternal and newborn care in urban areas: the example of Delhi

\begin{tabular}{|ll|}
\hline Sector & Provider \\
\hline Public sector & Delhi government \\
& Central government \\
& Municipal corporation \\
& New Delhi municipal corporation \\
& Employees' State Insurance \\
& Central Government Health Scheme \\
& Railways \\
& Cantonment \\
Private sector & Corporate hospitals \\
& Large private hospitals \\
& Small private hospitals \\
& Nursing and maternity homes \\
& Non-government organizations \\
& Individual practices: allopathic, AYUSH, combination \\
& Traditional birth attendants \\
\hline
\end{tabular}

\section{REPRODUCTIVE, MATERNAL, NEWBORN AND CHILD HEALTH +ADOLESCENT (RMNCH+A) STRATEGY}

$\mathrm{RMNCH}+\mathrm{A}$ calls for a continuum of care over the life cycle and distinguishes adolescence as a distinct life stage. In urban areas, the strategy focuses on unreached people in underserved localities, particularly slum dwellers, the homeless, street children, rag pickers, temporary migrants and construction workers. A systematic plan has been developed for urban areas, including a service package summarized in Figure 8.

$\mathrm{RMNCH}+\mathrm{A}$ will be monitored with a scorecard covering 16 indicators. Newborn indicators include the proportion of infants who initiated breastfeeding within one hour, discharged after $48 \mathrm{~h}$ of delivery, low birth weight and have been visited within $24 \mathrm{~h}$ of home deliveries.

\section{CHALLENGES FOR URBAN NEWBORN HEALTH}

Inequalities

Nearly every city in the country has pockets of extreme deprivation together with extreme wealth. There are people who overconsume healthcare and people who forego the most basic and essential care for financial and other reasons. There is no doubt that India's town and cities enjoy a health advantage, but it has become increasingly obvious that the net benefits of urban living conceal substantial inequalities. ${ }^{29}$

In order to see the effects of the social determinants of health, there is a need to view urban data with a greater depth of focus. The Urban Health Resource Centre analyzed the NFHS-3 (20052006) findings in Delhi and six states, and showed that women in the poorest quartile were substantially less likely to make at least three antenatal care visits ( 54 vs $83 \%$ ) and to have a birth assisted by a health provider. Their children had higher under-five mortality rates, lower immunization rates (40 vs 65\%) and higher proportion of stunting (54 vs $33 \%)^{30}$

A study involving about 300 mothers from 11 slums in Indore examined birth preparedness: $70 \%$ of mothers identified a birth attendant, 30\% arranged for transport, $77 \%$ saved money in advance. ${ }^{31}$ At a tighter level of focus, a study in 48 areas in Mumbai demonstrated clear inequalities between socioeconomic groups even though all the participants lived in slums. ${ }^{32}$ There was a stepwise increase from the lowest to the highest quartile in utilization of antenatal care, consumption of iron and folic acid supplements during pregnancy, and institutional delivery, and a stepwise decrease in teenage pregnancy and low birth weight. ${ }^{33}$

\section{ENVIRONMENTAL CHALLENGES AND THE NEED FOR CONVERGENCE}

Communities residing in slums often suffer deficiencies in water supply and sanitation. ${ }^{34}$ Poor housing fabric, poor ventilation and indoor pollution, and the density of homes contribute to the spread of infectious diseases and the burden of respiratory illness. Many homes are close to sources of industrial smoke and toxins, contaminated areas such as garbage dumps and water bodies, or hazards such as railway lines. The mandate for provision of municipal services is unclear when settlements are not legally notified and their residents do not have tenure ${ }^{35}$ with implications for water supply and collection of waste. There is a lack of coordination between the relevant departments ${ }^{27}$ and absence of convergence between infrastructural (water and sanitation, housing, transport) and health domains. 


\section{PUBLIC SECTOR HEALTHCARE CONCERNS}

There are two general concerns for newborn healthcare: quantity and quality. In terms of quantity, available health services in medium-sized cities where slums are present without municipal corporations is a critical gap. Also, the social exclusion experienced by residents of unlisted slum areas extends to provision of healthcare facilities and outreach. ${ }^{35}$

The varying quality of public healthcare is the product of a matrix of infrastructural weakness, deficiencies in equipment and consumables, human resource shortfalls, and limited provider competencies. For maternal and newborn care, there is a lack of norms for service provision at different levels of healthcare facilities. No protocols exist for identifying women at risk and referring them for specialized care. Referral chains have been undefined and based more on a hospital's reputation and bed availability than on a regional plan, and referrals themselves have been unsystematic. ${ }^{35,36}$ Clients are sent to hospitals that have not been warned and may not have beds, the paper trail is sketchy, accountability is minimal and transport is often the responsibility of the family.

\section{PRIVATE SECTOR HEALTHCARE CONCERNS}

A central issue is the multiplicity of providers, ${ }^{37}$ with limited accreditation and quality assurance. ${ }^{38-41}$ Despite the policy emphasis on state and municipal healthcare provision, $80 \%$ of outpatient consultations in India are with private providers. This is illustrated by the predominant use of non-government services in both slum and non-slum areas (with little way to distinguish between them). ${ }^{8}$ Private healthcare clusters in towns and cities, and-through a self-organizing complex system that takes into account ability to pay-serve both the poor and the wealthy. ${ }^{42,43}$ The kinds of services available in Delhi are summarized in Table 2.

A study of 261 private hospitals in 10 districts of Maharashtra (India's second most urbanized state) confirmed the rising use of private care. Many hospitals are understaffed-particularly in terms of qualified healthcare workers: more than half did not have a single qualified nurse at the time of the study-and accreditation was limited. ${ }^{44}$ Countrywide, $86 \%$ of the healthcare expenditure is out-of-pocket. ${ }^{45}$

Reports of malpractice, over-medication, inappropriate prescription practices and treatments, and excessive use of diagnostic tests are common. ${ }^{37}$ Payments for healthcare delivery at a private health centre are about three times those for a public facility. ${ }^{46}$ Out-of-pocket payments can be impoverishing. ${ }^{47}$ Expenditure on maternity often requires borrowing and can be catastrophic for poor households. ${ }^{48}$ Often, record keeping is poor and the data is seldom used for improving services.

There have been efforts to ease the situation including some form of partnership between private and public sector hospitals. Following the grant of concessional land allotment rates to private hospitals in Delhi, they are expected to allot 10\% of inpatient beds and $25 \%$ of outpatient consultations free of charge to clients with monthly incomes of less than Rs. $4000 .^{49}$

\section{IDENTIFYING BENEFICIARIES AND CLOSING DATA GAPS}

Data on the vulnerable population in urban areas is grossly incomplete and missing out a sizable number of unlisted slums in any city. A need for targeting the most vulnerable as well as addressing the needs of the differentially vulnerable requires identification, mapping and assessment of all slums in order to locate the hitherto missed slums and the most needy.

Most cities lack epidemiological data, information on the urban poor and illegal clusters, and information on private health facilities. ${ }^{35}$ India's cities also lack information management systems that can help with urban planning, particularly in terms of slum areas. $^{50}$

Hidden Cities, a report by the WHO and UN-Habitat, reveals the urban health inequities that are the result of the circumstances in which people grow, live, work and age, and the healthcare systems they can access. ${ }^{51}$ The report demonstrates that the aggregated data often mask substantial health inequities within urban populations-inequities that are revealed when this same information is disaggregated according to defining characteristics of city dwellers such as their socioeconomic status or place of residence.

\section{CONCLUSION}

India is urbanizing rapidly with an expectation that the urban population will be almost 600 million by 2030. National health survey data demonstrate that overall neonatal mortality rates are lower in urban areas but the figures mask substantial urban inequalities. Recent data also suggest a relative lack of progress in reducing early neonatal mortality.

Socioeconomic inequalities and environmental concerns pose major challenges for newborn health. Healthcare is concentrated in urban areas but health outcomes are subject to variation in pluralistic provision and a lack of clarity in protocols, communication, referral and transport between institutions. Fragmented and weak public healthcare systems, a multiplicity of actors, and limited public health planning capacity compromise the delivery of affordable quality healthcare. However, a number of pilot initiatives have begun, including private-public partnerships, community action models, demand side financing and insurance, but evaluation has been limited.

Within the NHM, the NUHM provides an opportunity for strategic thinking and actions to improve urban newborn health. $\mathrm{RMNCH}+\mathrm{A}$ initiative adds to this an opportunity to integrate healthcare over the life cycle.

\section{RECOMMENDATIONS ON NEWBORN HEALTH IN URBAN INDIA}

- Develop workable and feasible models of maternal and newborn care for urban populations with focus on the poor within the NUHM framework. (Alternatively, frame newborn in the $\mathrm{RMNCH}+\mathrm{A}$ continuum).

- Develop convergence mechanisms of public, private and third sector institutions whose work impacts urban newborn health: water and sanitation, urban planning, transport and building all have a role.

- Develop platforms for harmonization and sharing of data: to provide epidemiologic and evaluative insights for programming.

- Review and redefine the roles of urban local bodies in public health including newborn health.

- A multipronged strategy to make health care service delivery effective and affordable is much required. The focus needs to be on the making health service delivery of high quality and affordable. Training, deployment and support for human resources for urban healthcare remain central to efforts to improve newborn survival.

- Define staffing norms for urban healthcare facilities, public and private and within and outside NUHM.

- Involve civil society and NGOs for effective implementation of the urban newborn health programs.

- Partner with professional bodies like NNF, IAP and FOGSI (Federation of Obstetric and Gynaecological Societies of India) for service delivery, to develop standard norms and protocols, training and quality assurance.

- Conduct implementation research to demonstrate sustainable models of newborn healthcare

.




\section{CONFLICT OF INTEREST}

Benazir Patil and Rajesh Khanna are affiliated to Saving Newborn Lives, Save the Children, India (Sponsor of the Supplement). Remaining authors declare no competing interests.

\section{ACKNOWLEDGEMENTS}

Support for this publication was provided by Save the Children's Saving Newborn Lives program.

\section{REFERENCES}

1 Government of India, MInistry of Home Affairs. Census of India 2011. Provisional population totals. Urban agglomerations and cities. Available at http://cen susindia.gov.in/2011-prov-results/paper2/data_files/India2/1.\%20Data\%20High light.pdf.

2 McKinsey Global Institute. India's urban awakening: building inclusive cities, sustaining economic growth. In: McKinsey \& Company, 2010.

3 Verma M. Recommended policy guidelines for public health. A report to the Municipal Corporation of Greater Mumbai and the Non-Governmental Organization Council. In. Mumbai. www.karmayog.org, 2006.

4 Yadav K, Nikhil SV, Pandav CS. Urbanization and health challenges: need to fast track launch of the National Urban Health Mission. Indian J Community Med 2011; 36: 3-7.

5 HPEC. Report on Indian urban infrastructure and services. In. New Delhi: High Powered Expert Committee (HPEC) for estimating the investment requirements for urban infrastructure services, 2011.

6 Office of the Registrar General \& Census Commissioner. Sample Registration System statistical report 2010. estimates of fertility indicators. in. New Delhi: Government of India, Ministry of Home Affairs, 2010

7 Goli S, Arokiasamy P, Chattopadhayay A. Living and health conditions of selected cities in India: setting priorities for the National Urban Health Mission. Cities 2011; 28: 461-469.

8 Agarwal S, Taneja S. All slums are not equal: child health conditions among the urban poor. Indian Pediatr 2005; 42: 233-244.

9 Planning Commission. Press note on poverty estimates, 2011-2012. In. New Delhi: Government of India, 2013.

10 Planning Commission. Steering Committee on Urbanization. Report of the working group on urban poverty, slums, and service delivery system. Available at: http://planningcommission.nic.in/aboutus/committee/wrkgrp12/hud/wg_Final_ Urb_Pvt.pdf.

11 More NS, Alcock G, Das S, Bapat U, Joshi W, Osrin D. Spoilt for choice? Crosssectional study of care-seeking for health problems during pregnancy in Mumbai slums. Glob public health 2011; 6: 746-759.

12 Census of India: Registrar General of India. Sample Registration System (SRS) statistical report. In. New Delhi, 2013.

13 Office of the Registrar General \& Census Commissioner- Ministry of Home Affairs, Govt. of India. Annual health survey. Available at: http://www.censusindia.gov.in/ 2011-Common/AHSurvey.html.

14 Bapat U, Alcock G, More NS, Das S, Joshi W, Osrin D. Stillbirths and newborn deaths in slum settlements in Mumbai, India: a prospective verbal autopsy study, India: a prospective verbal autopsy study. BMC Pregnancy Childbirth 2012; 12: 39.

15 Vaid AM, A. Primrose B., Kang G.. Infant mortality in an urban slum. Indian J Pediatr 2007; 74: 449-453.

16 Rydin Y, Bleahu A, Davies M, Dávila JD, Friel S, De Grandis G et al. Shaping cities for health: complexity and the planning of urban environments in the 21st century.. Lancet. 379: 2079-2108.

17 Mavalankar D, Singh A, Patel SR, Desai A, PV S. Saving mothers and newborns through an innovative partnership with private sector obstetricians: Chiranjeevi scheme of Gujarat. Int J Gynaecol Obste 2009; 107: 271-276.

18 Singh A, Mavalankar DV, Bhat R, Desai A, Patel SR, Singh PV et al. Providing skilled birth attendants and emergency obstetric care to the poor through partnership with private sector obstetricians in Gujarat, India. Bull World Health Organ 2009; 87: $960-964$.

19 Bhat R, Mavalankar DV, Singh PV, Singh N. Maternal healthcare financing: Gujarat's Chiranjeevi Scheme and its beneficiaries. J Health, Popul Nutr 2009; 27: 249-258.

20 Awasthi S, Srivastava NM, Agarwal GG, Pant S, Ahluwalia TP. Effect of behaviour change communication on qualified medical care-seeking for sick neonates among urban poor in Lucknow, northern India: a before and after intervention study. Trop Med Int Health 2009; 14: 1199-1209.

21 Aggrawal S. Developing Collective Community Leadership for Better Health of the Urban Poor. In: Fourth International Conference on Transforming Development to Alleviate Poverty and Climate Change. IDCA: New Delhi, India, 2008.
22 Khan Z, Mehnaz S, Khalique N, Ansari MA, Siddiqui AR. Poor perinatal care practices in urban slums: possible role of social mobilization networks. Indian J Community Med 2009; 34: 102-107.

23 Fernandez A, Osrin D. The city initiative for newborn health. PLoS Med 2006; 3: e339.

24 Prost A, Colbourn T, Seward N, Azad K, Coomarasamy A, Copas A et al. Women's groups practising participatory learning and action to improve maternal and newborn health in low-resource settings: a systematic review and meta-analysis. Lancet 2013; 381: 1736-1746.

25 More NS, Bapat U, Das S, Alcock G, Patil S, Porel M et al. Community mobilization in Mumbai slums to improve perinatal care and outcomes: a cluster randomized controlled trial. PLoS Med 2012; 9: e1001257.

26 PATH sure start zindagi aayi kushiyan laye, sure statrt ke sang. Available at: http://www.path.org/publications/files/CP_india_sure_start_bro.pdf. Accessed 11 December 2014.

27 National Urban Health Mission Framework for Implementation. In. New Delhi National Health Mission, Ministry of Health and Family Welfare, Govt. of India, 2013.

28 Making the Urban Health Mission work for the urban poor: Executive summary Report of Technical Resource Group. In. Minstry of Health and Family Welfare, Govt. of India: New Delhi, India, 2014.

29 Matthews Z, Channon A, Neal S, Osrin D, Madise N, Stones W. Examining the "urban advantage" in maternal health care in developing countries. PLoS Med 2010; 7: e1000327.

30 Agarwal S. The state of urban health in India; comparing the poorest quartile to the rest of the urban population in selected states and cities. Environ Urban 2011; 23: 13-28.

31 Agarwal S, Sethi V, Srivastava K, Jha PK, Baqui AH. Birth preparedness and complication readiness among slum women in Indore city, India. $J$ Health, Popul Nutr 2010; 28: 383.

32 More N, Bapat U, Das S, Barnett S, Costello A, Fernandez A et al. Inequalities in maternity care and newborn outcomes: one-year surveillance of births in vulnerable slum communities in Mumbai. Int J Equity Health 2009; 8: 21.

33 Subbaraman R, O'Brien J, Shitole T, Shitole S, Sawant K, Bloom DE et al. Off the map: the health and social implications of being a non-notified slum in India. Environ Urban 2012; 24: 643-663.

34 Subbaraman R, Shitole S, Shitole T, Sawant K, O'Brien J, Bloom DE et al. The social ecology of water in a Mumbai slum: failures in water quality, quantity, and reliability. BMC Public Health 2013; 13: 173.

35 Agarwal S, Satyavada A, Kaushik S, Kumar R. Urbanization, urban poverty and health of the urban poor: status, challenges and the way forward. Demography India 2007; 36: 121.

36 Agarwal S. Improving urban newborn health: challenges and the way forward. J Neonatol 2009; 23: 208.

37 Radwan I.. India - Private Health Services for the Poor. Policy Note 33579. In. The International Bank for Reconstruction and Development/World Bank: Washington, DC, USA, 2005; 37-38.

38 Barua N.. How to Develop a Pro-poor Private Health Sector in Urban India?. In Global Forum for Health Research - Forum 9: Mumbai, India, 2005.

39 Das J, Hammer J. Money for nothing: the dire straits of medical practice in Delhi, India. J Dev Econ 2007; 83: 1-36.

40 Das J, Hammer J, Leonard K. The quality of medical advice in low-income countries. J Econ Perspect 2008; 22: 93-114.

41 Das J. The quality of medical care in low-income countries: from providers to markets. PLoS Med 2011; 8: 488.

42 Bhatia JC, Cleland J. Health-care seeking and expenditure by young Indian mothers in the public and private sectors. Health Policy Plan 2001; 16: 55-61.

43 de Zoysa I, Bhandari N, Akhtari N, Bhan MK. Careseeking for illness in young infants in an urban slum in India. Soc Sci Med 1998; 47: 2101-2111.

44 Bhate-Deosthali P, Khatri R. Private health sector in Maharashtra: a study of private hospitals. In: Center for Enquiry into Health and Allied Themes(CEHAT), 2011:1-8.

45 The World Bank Group IBRD.IDA. Out-of-pocket health expenditure (\% of private expenditure on health). Available at: http://data.worldbank.org/indicator/SH.XPD. OOPC.ZS.

46 Mohanty SK, Srivastava A. Out-of-pocket expenditure on institutional delivery in India. Health policy and planning 2012:czs057.

47 Ghosh S. Catastrophic Payments and Impoverishment due to Out-of-Pocket Health Spending. Econ Polit Wkly 2011; 46: 63-70.

48 Skordis-Worrall J, Pace N, Bapat U, Das S, More NS, Joshi W et al. Maternal and neonatal health expenditure in mumbai slums (India): A cross sectional study. BMC Public Health 2011; 11: 150.

49 Government of India. Supreme Court. Guidelines for provision of free treatment facilities to patients of EWS category in private hospitals in pursuance of 
directions issued by the Hon'ble High Court of Delhi in WP(C) no 2866/2002 in the matter of Social Jurist Vs GNCT Delhi. available at: http://www.delhi.gov.in/ wps/wcm/connect/3cd0a5004d9238eeaa5eaf09e0ee946a/guidelines.pdf?MOD = AJPERES.

50 Ministry of Housing and Urban Poverty Alleviation. Report of the Committee on Slum Statistics/Census. In. National Buildings Organisation, Government of India: New Delhi, India, 2010.

51 Hidden cities: unmasking and overcoming health inequities in urban settings. In: World Health Organization, The WHO Centre for Health Development, Kobe and United Nations Human Settlements Programme (UN-HABITAT), 2010.
(7) $\Theta$ This work is licensed under a Creative Commons Attributioncc. NonCommercial-NoDerivs 4.0 International License. The images or other third party material in this article are included in the article's Creative Commons license, unless indicated otherwise in the credit line; if the material is not included under the Creative Commons license, users will need to obtain permission from the license holder to reproduce the material. To view a copy of this license, visit http:// creativecommons.org/licenses/by-nc-nd/4.0/

(c) The Author(s) 2016 